\title{
Aportacions i referències etnopoètiques en l'obra literària de Carmelina Sánchez-Cutillas
}

\section{Ethnopoetic contributions and references in the literary creations of Carmelina Sánchez-Cutillas}

\author{
JOAN BORJA I SANZ \\ joan.borja@ua.es \\ Universitat d'Alacant
}

\begin{abstract}
Resum: L'obra literària de Carmelina Sánchez-Cutillas inclou abundants aportacions i referències etnopoètiques que resulten interessants no solament per a l'estudi del folklore, sinó també -i molt especialment- com a elements estratègics en la construcció d'uns discursos memorialístics que adesiara tendeixen a presentar els records objecte de literaturització embolcallats amb una mena de boirina màgica: una espècie de perspectiva difuminada que optimitza la propensió a la meravella de manera que el lector queda contagiat per la presumpta dificultat de la narradora a l'hora de «destriar els fets reals dels fantàstics».
\end{abstract}

Paraules clau: Carmelina Sánchez-Cutillas, Matèria de Bretanya, etnopoètica, rondalles, literatura popular valenciana

\begin{abstract}
Carmelina Sánchez-Cutillas' literary creations include abundant ethnopoetic references. These contributions are interesting not only for the study of folklore and also -and very especially- as strategic elements in the construction of discourse. The author's memorialistic prose frequently tends to present memories wrapped in a magical mist: a kind of blurred perspective that optimizes the propensity for wonder. In this way, the reader participates in an atmosphere where it is difficult to «distinguish the real facts from the fantastic». This article studies the contributions and ethnopoetic references present in the literary texts of Carmelina Sánchez-Cutillas as an epistemiological option that is considered relevant for a better understanding of the personal, poetic and captivating game of fusions, confusions, effusions and diffusions -on the imprecise and suggestive boundaries between reality, dream, memory, imagination, history and fiction- which, in the last analysis, is the literary work of this singular author.
\end{abstract}

Keywords: Carmelina Sánchez-Cutillas, Matter of Britain, ethnopoetics, folktales, Valencian folk literature

\footnotetext{
*Aquest article s'emmarca en una línia d'investigació que ha rebut finançament del Ministeri de Ciència, Innovació i Universitats a través del projecte Literatura popular catalana: gèneres, conceptes i definicions, PGC2018-093993-B-I00 (MCIU/ AEI/FEDER, UE).
}

DATA PRESENTACIÓ: 01/05/2021 ACCEPTACIÓ: 14/05/2021 ·PUBLICACIÓ: 01/06/2021 
Joan Borja i Sanz. Aportacions i referències etnopoètiques en l'obra literària de Carmelina Sánchez-Cutillas

D'acord amb Heda Jason (1977) entenem l'etnopoètica com la «branca del folklore que s'ocupa de les manifestacions artístiques de base verbal». És a dir: el conjunt de gèneres literaris d'autoria anònima i transmissió oral que tenen la capacitat de crear i recrear un determinat imaginari compartit. En un treball de referència imprescindible en la història de l'etnopoètica catalana, Carme Oriol (2002) distingia, entre altres, els gèneres etnopoètics següents: la rondalla, el mite, la llegenda, el relat sobre experiències reals, l'acudit, la fórmula (incloent-hi el motiu local, la fraseologia, l'endevinalla, l'enigma, la fórmula de fonació i la fórmula rimada) i la cançó.

Doncs bé: un dels elements estratègics en l'obra Matèria de Bretanya, de Carmelina Sánchez-Cutillas és, precisament, la referenciació i l'aprofitament de motius etnopoètics al servei del propòsit literari de l'obra, la qual, com és sabut, transcendeix l'estricta recreació de la memòria individual i col lectiva. «He escrit aquest grapat de fulls perquè volia rescatar, salvar de l'oblit tot un món d'éssers i de coses viscudes», justifica l'autora al principi del llibre (1976: 23). Tanmateix, el lector de Matèria de Bretanya descobrirà de seguida que, més enllà de la voluntat de preservació del món passat per mor de la facultat evocativa i redemptora de les paraules, també plana per tota l'obra una singular proposta de literaturització interpretativa del món, amb valors intemporals que es projecten des del passat literàriament recreat -un temps i un espai concrets: l'Altea immediatament anterior a la Guerra Civil- fins al present del lector que llig l'obra amb un abast significatiu il limitat, que clarament depassa aquest circumstancial ancoratge geogràfic $i$ temporal.

I és que, tant com la realitat literàriament recreada, en Matèria de Bretanya resulta rellevant la mirada amb què tal realitat ens és presentada. El fet que el jo discursiu dels vint-i-nou «contets d'eixos» que integren l'obra ${ }^{1}$ siga assumit en primera persona per la veu de la xiqueta que al seu dia va ser la mateixa autora, contribueix decisivament a embolcallar el conjunt de «Els fets» narrats amb un aire d'ingenuïtat, imprecisió i innocència que resultarà altament estratègic i productiu a l'hora de vehicular les percepcions crítiques de l'autora respecte d'algunes eixos ideològics determinats, com ara el de la desigualtat social, el de la religió, el de l'opressió del poder, el del condicionament per raó de gènere, el del contrast entre el poble i la ciutat $\mathrm{o}$, molt especialment, el de les abstraccions de la cultura i la identitat.

La veu de la xiqueta que un dia va ser Carmelina Sánchez-Cutillas en aquells remots, ingenus, innocents i enyorats dies de la infantesa viscuda a Altea a finals dels anys vint i les primeries dels

1 Matèria de Bretanya consta d'una breu introducció d'un parell de pàgines, intitulada «L'origen» (1976: 23-24), seguida d'una segona part, presentada amb el títol genèric «Els fets». Aquesta segona part, que és en realitat el cos del llibre, consta al seu torn de vint-i-nou capítols. L'expressió «un contet d'eixos» per a referir-se a cadascun d'aquests vint-i-nou capítols, no exempta d'un evidentíssim to de modèstia, és de la mateixa Carmelina Sánchez-Cutillas. La va fer servir en el context de l'entrevista que vam tenir l'oportunitat de fer-li per a Ràdio Altea, a sa casa del carrer Cronista Carreres, el maig de 2008. El seu fill, Luis del Romero Sánchez-Cutillas, en va voler recuperar l'expressió en La meva cambra més estimada (2020: 109). 
Joan Borja i Sanz. Aportacions i referències etnopoètiques en l'obra literària de Carmelina Sánchez-Cutillas

anys trenta del segle vint ${ }^{2}$ legitima que els personatges, els objectes, els paisatges, els esdeveniments i els costums siguen percebuts i presentats - per dir-ho així- amb una aurèola de meravella: com si l'ull que mira i interpreta estiguera dotat d'una espècie de filtre màgic, fantàstic, líric i idealitzant que modalitza literàriament el món observat. És d'aquesta manera que, en l'últim capítol de l'obra -que és el que dona nom i dota de sentit tot el conjunt-, Carmelina Sánchez-Cutillas apel la a l'alquímia de la literatura i la cultura escrivint: «i encara que tot era igual, igual com ahir i com sempre, a mi em semblava diferent, perquè aqueixa vesprada havia après a idealitzar els fets del passat $\mathrm{i}$ tots els esdeveniments de cada dia, havia après a embolcallar-los d'aventures i de situacions meravelloses per a velar, amb un toc mític, els successos reals» (1976: 195). És precisament això -aquesta idealització, aquest embolcall d'aventura, aquesta aura de meravella, aquest toc mític- el que la mateixa autora sembla reivindicar amb la seua obra: una personal poetització de la quotidianitat i del món passat, virada d'emoció i de prodigi, amb l'indissimulat propòsit de reinterpretar i significar literàriament la realitat vital immediata. I és obvi que, per a aquesta finalitat, les referències etnopoètiques llegendàries, rondallístiques, fraseològiques, relatives a cançons, etc.- oferien, tant per a l'evocació com per a aquesta poetització de la realitat, una gran eficàcia al servei de la seua exquisida prosa memorialística.

\section{1. «La mare Paula ens contava contes»}

El personatge que potser encarna d'una manera més clara i evident la instrumentalització de referències etnopoètiques al servei del propòsit literari últim de Matèria de Bretanya és el de la mare Paula. Es tracta de la protagonista del vuité capítol, «Remembrança». Representa, emblemàticament, una espècie de matriarca popular -una mare vella, sàvia, acollidora, protectora i bondadosa- que nodreix les vides, les imaginacions i les esperances de totes les xiquetes i tots els xiquets del món. Impossible no entendrir-se amb la figura d'aquest personatge, per poc que parem atenció a les pinzellades literàries amb què Carmelina n'encara la descripció: «era tan vella que caminava a poquet a poquet amb el cap mirant a terra»; «el seu rostre estava ple d'arrugues com si foren caminets de temps i per cada caminet aplegàs un record»; «li dèiem mare Paula, i quan érem al seu costat sentíem una caloreta com d'estar al costat de la mare»; «però un dia va morir la mare Paula, i tota la menudalla l'acompanyàrem al cementeri»; «i quan els grans soterraren la mare Paula, nosaltres, els nins, vam soterrar moltes coses»; etc.

\footnotetext{
2 Fins ara s'havia acceptat i respectat la convenció, expressament reivindicada en vida per l'autora, de l'any 1927 com a data del naixement. Tanmateix, a finals de març de 2021 es va començar a fer pública la veritable data de naixement segons consta en el certificat de defunció: el 23 de juny de 1921. Això explica, per exemple, que l’autora puga conservar records de l'episodi de la insurrecció de Jaca, el desembre de 1930, i de l'afusellament dels capitans Fermín Galán i Ángel García Hernández, els quals, segons una hipòtesi absolutament plausible que dec a l'escriptor i investigador Víctor Gómez Labrado, devien ser els «dos homes afusellats» protagonistes del capítol «Un fermallet rodó» (1976: 165-169).
}

SCRIPTA, Revista internacional de literatura i cultura medieval i moderna, núm. 17 / juny 2021 / pp. ISSN: $2340-4841 \cdot$ doi:10.7203/SCRIPTA.17.20924 
Joan Borja i Sanz. Aportacions i referències etnopoètiques en l'obra literària de Carmelina Sánchez-Cutillas

El passatge en què Carmelina descriu, en la part central del capítol, els berenars a base de pa i melva amb què la mare Paula obsequiava la xicalla del poble les vesprades que plovia (1976: 6668) constitueix una habilíssima manipulació del caràcter alhora particular i universal del patrimoni rondallístic al servei d'aquest propòsit literari de voler recrear «amb un toc mític» «els fets del passat i tots els esdeveniments de cada dia». Perquè, si el pa i la melva reïfiquen en aquest passatge l'aliment del cos, les rondalles que la mare Paula contava a les xiquetes i els xiquets s'han d'entendre, en paral lel, com una mena d'aliment per a l'esperit, amb bones llesques d'imaginació i prou molletes de fantasia. Per això mereixen ser assimilades simbòlicament al «coret de la melva» que les criatures hi disputaven: «perquè quan ens el menjàvem era com menjar-se una cosa tèbia, i sentíem un caliu per dintre com si el nostre cor volgués créixer una miqueta» (1976: 67), de manera que, al final del passatge, aquest cor podrà ser représ anafòricament de la manera següent:

I és possible fins i tot que tots els xiquets del món hagen tingut una mare Paula, i que estimen la pluja lleu que fa gloc gloc gloc quan rellisca del cel, i que en menjar-se els corets de la melva sentiran també créixer els seus petits cors (1976: 67-68).

El fet que Carmelina suggerisca això, que «és possible fins i tot que tots els xiquets del món hagen tingut una [mateixa] mare Paula», evidencia que, si més no en un nivell intuïtiu, la nostra autora devia ser perfectament coneixedora dels principis de l'anomenat mètode historicogeogräfic de l'escola finesa en l'estudi de la rondallística internacional, el qual parteix, precisament, de la constatació que en la rondallística universal hi ha una determinat repertori d'arquetips rondallístics que es reprodueixen en les diferents llengües i cultures, per la qual cosa aquests arquetips poden ser definits, tipificats i catalogats en índexs internacionals. Aquest repertori de narracions recurrents d'abast universal no deixa de ser una mena de substràtum, font o repositori comú de fantasies compartides per infants de pobles, identitats i nacions diferents: una «mare Paula» universalment compartida per «tots els xiquets del món».

Hem de parar esment, en aquest sentit, en un detall altament significatiu que l'autora aporta per reforçar aquesta idea de la universalitat i la particularitat de les rondalles a propòsit de la seua rondalla favorita:

\footnotetext{
Quan ja havíem menjat boes llesques de pa i prou molletes de melva, la mare Paula ens contava contes. El que més m'agradava de tot el repertori era el de «Peret i Margaliteta». Després, en fer-me gran, vaig adonar-me que aquest conte es diu «Hansel und Gretchen» i que el saben tots els xiquets del món (1976: 67).
}

Fet i fet, sense fer-ho explícit, Carmelina s'està referint amb aquesta anècdota al fet que el conte valencià de «Peret i Margaliteta» que la mare Paula contava a Altea pot ser assimilat al tipus internacional ATU 327A, universalment conegut amb el títol «Hansel and Gretel» i caracteritzat, segons The Types of International Folktales pel resum següent: 
Joan Borja i Sanz. Aportacions i referències etnopoètiques en l'obra literària de Carmelina Sánchez-Cutillas

\begin{abstract}
Hansel and Gretel. A (poor) father (persuaded bay the stepmother) abandons his children (a boy and a girl) in the forest. Twice the children find their way back home, following scattered pebbles. On the third night, birds eat the scattered peas (bread-crumbs).

The children come upon a gingerbread house which belongs to a witch (ogress). She takes them into her house. The boy is fattened, while the girl must do housework. The witch asks the boy to show his finger in order to test how fat he is, but he shows her a bone (stick). When the witch wants to cook the boy, the sister deceives her by feigning ignorance and pushes her into the oven. (The witch's son finds out that his mother has been killed and pursues the children.)

The children escape, carrying the witch's treasure with them. Birds and beast (angels) help them across water. They return home (Uther 2004: 212). ${ }^{3}$
\end{abstract}

Una dècada després de l'obtenció del Premi Andròmina en els Premis Octubre de 1975 amb Matèria de Bretanya, Carmelina recordarà encara el personatge de la mare Paula i aquest motiu rondallístic de «Peret i Margaliteta» en el text mecanoscrit que redactarà per a l'acte de presentació del llibre de Joaquim Gonzàlez Caturla Rondalles de l'Alacantí: un acte que va tindre lloc a Alacant el maig de $1985 .{ }^{4}$ En aquesta altra ocasió, l'autora, a propòsit de la versió recollida i recreada per l'autor alacantí, observarà:

També han retornat a mi, des de la cendra, les imatges boiroses de la Mare Paula, de Maria la Canària, de Quica Ronda... Anys i més anys, per a trobar les mateixes faules que van entretenir la meua infantesa. [...] La versió de «Peret i Margariteta» que corria per la meua contrada es semblava més que aquesta al «Hänsel und Gretel» de Grimm. La caseta del bosc feta de sucre, de torró, de xocolate i de totes les llepolies del món, amb la bruixa que empresonava els xiquets tafaners, és una imatge que jo i molts dels meus companys de jocs guardem encara en la memòria. El relat que fa de la mateixa rondalla el professor Gonzàlez Caturla, arreplegat a Sant Joan i Mutxamel, és més esgarrifós. ${ }^{5}$

\footnotetext{
3 Aquest tipus 327A apareix ja documentat l'any 1698 en Finette Cendron, de Madame d'Aulnoy, i pot ser documentat, entre altres, en les literatures següents: finesa, suecofinesa, estoniana, livoniana, letona, lituana, sami, vepsa, sueca, danesa, feroesa, islandesa, irlandesa, espanyola, catalana, portuguesa, frisona, flamenca, valona, alemanya, ladiniana, italiana, corsa, maltesa, hongaresa, txeca, eslovaca, eslovena, sèrbia, croata, romanesa, búlgara, grega, polonesa, sòrab, russa, bielorussa, ucraïnesa, jueva, gitana, adigué, txuvaix, mordoviana, mansi, txeremissa, mongola, síria, iraquiana, iemenita, índia, xinesa, coreana, indonèsia, japonesa, dels indis nord-americans, hispanoamericana, mexicana, costariquenya, panamenya, cubana, dominicana, porto-riquenya, colombiana, maia, equatoriana, peruana, brasilera, xilena, de les Índies Occidentals, egípcia, tunisiana, algeriana, marroquina, sudanesa, namibiana i malgaixa (Uther 2004: 212-213).

4 Aquest acte de presentació va ser, exactament, el dijous 30 de maig de 1985, a les 20:00 h, a l'Aula de Cultura de la Caixa d'Estalvis d'Alacant i Múrcia. La participació de Carmelina en l'esdeveniment va ser possible gràcies a la intermediació del poeta Emili Rodríguez-Bernabeu, amic comú de tots dos autors. En una carta de Joaquim Gonzàlez Caturla adreçada el 18 de maig de 1985 a Carmelina Sánchez-Cutillas amb motiu de la tramesa del llibre Rondalles de l'Alacantí (carta que es conserva en la caixa 17 de l'Arxiu Carmelina Sánchez-Cutillas i Martínez en la Biblioteca Valenciana Nicolau Primitiu), no solament trobem explicitats el dia, el lloc i l'hora de l'acte de presentació d'aquest llibre, sinó també uns saborosos apunts de l'autor alacantí sobre el procés d'elaboració i la metodologia seguida en la literaturització de les trenta-sis narracions populars que integren aquest llibre de Rondalles de l'Alacantí.
}

5 Aquest mecanoscrit de Carmelina es conserva en la caixa 17 de l'Arxiu Carmelina Sánchez-Cutillas i Martínez en la Biblioteca Valenciana Nicolau Primitiu. El document serà donat a conéixer íntegrament en l'edició de l'obra completa que, conjuntament amb M. Àngels Francés, estem preparant per a l'Acadèmia Valenciana de la Llengua amb motiu de

SCRIPTA, Revista internacional de literatura $i$ cultura medieval i moderna, núm. 17 / juny 2021 / pp. 
Joan Borja i Sanz. Aportacions i referències etnopoètiques en l'obra literària de Carmelina Sánchez-Cutillas

Es refereix, Carmelina, ací, al segon dels relats recopilats per Caturla en les seues Rondalles de l'Alacantí, «Peret i Margariteta» (Caturla 1985: 31-34). És del tot comprensible que l'autora perceba intuïtivament que la versió de la mare Paula al ludida en Matèria de Bretanya era molt més pròxima al conte de «Hänsel und Gretel» publicat pels germans Grimm, per la senzilla raó que la versió recollida per Caturla a Sant Joan i Mutxamel no és ben bé la corresponent al citat tipus ATU 327A, sinó més aïna una versió del tipus ATU 720, The Juniper Tree (anteriorment identificat amb el títol My Mother Slew Me; My Father Ate Me), o bé del tipus ATU $780 .{ }^{6}$

\section{2. «A caçar gambosins i a espigolar seguissets»}

En la caixa 10 de l'Arxiu Carmelina Sánchez-Cutillas de la Biblioteca Valenciana Nicolau Primitiu es conserva l'esborrany d'una carta per a la resposta que l'escriptora estava preparant a una missiva enviada des d'Alacant pel professor Lluís Alpera durant el procés d'edició de l'Obra poètica de Carmelina, l’any 1997, en la col lecció «Els Quatre Vents» del Consell Valencià de Cultura. Alpera li

l'Any Carmelina Sánchez-Cutillas. Fora interessant, en un futur, atendre, també, com un complement a les aportacions fetes en l'obra literària que constitueixen l'objecte d'estudi d'aquest article, les contribucions fetes per Carmelina en el camp dels estudis etnopoètics més enllà de l'obra estrictament literària. En aquest sentit, el document mecanoscrit de la presentació del llibre Rondalles de l'Alacantí resulta summament interessant, per tal com Carmelina hi exhibeix uns coneixements extraordinaris sobre etnopoètica universal, amb un veritable luxe de referències erudites a Les mil $i$ una nits, Simbad, Robinson, Heròdot d'Halicarnàs, Llucià de Samòsata, Cebes, Dió Crisòstom, Caritó d'Afrodísies, Apol loni de Tir, Ciceró, Petroni, Apuleu, Llucià de Patres, l'infant Joan Manuel, Pedro Alfonso, Calila i Dimna, el Llibre de les bèsties i el Llibre de contemplació en Déu de Llull, La disputa de l'ase de Turmeda, els fabliaux francesos, El libro de Sendebar, Barlaam i Josafat, Manuel Milà i Fontanals, Lo procés de les olives i disputa dels jóvens i dels vells, Joan de Timoneda i el seu pròleg a El patrañuelo, Carles Ros i Lluís Galiana, L’Espill de Jaume Roig, Teodor Llorente, Joaquim Martí i Gadea, Francesc Martínez i Martínez, Francesc Badenes i Dalmau, Josep Pasqual Tirado, Enric Valor i Vives, Perrault, els germans Grimm, Christian Andersen, Saturnino Calleja, les Faules d'Isop, el Llibre dels set savis de Roma, el Novel lari català de Miquel i Planas i, òbviament, l'obra del mateix Joaquim Gonzàlez i Caturla. Altres contribucions que igualment caldria tenir en compte en aquest treball pendent d'execució són, per descomptat, la «Semblança de don Francesc Martínez i Martínez» (Sánchez-Cutillas 1970) i la monografia biobibliogràfica Francisco Martinezy Martínez: Un bumanista alteano (1866-1946) (Sánchez-Cutillas 1974).

6 El resum aportat per Uther (2004: 389) per al tipus 720 és: «A childless couple wishes for a child. A boy is born but his mother dies. The little boy is slain by his cruel stepmother who closes the lid an apple chest on him. She cooks him and serves him to his father who etas him unwittingly. / The boy's stepsister gathers up his bones and puts them under a juniper tree. A bird comes forth and sings about what happened. It brings presents to the father and the sister and drops a millstone to the stepmother, filling her. The boy is resuscitated». Oriol i Pujol (2003: 200-202), tanmateix, van catalogar aquesta narració de Joaquim Gonzàlez Caturla com a tipus ATU 780, «The Singing Bone», molt semblant al 720: «A brother (sister) kills his (her) brother (sister) and burles him (her) in the earth. From the bones a shepherd makes an instrument (harp, violin, flute) which brings the secret to light. / Or the murder is revealed by a (speaking) tree growing from the grave». Ben mirat, el relat popular valencià que Joaquim G. Caturla recull amb el títol de «Peret i Margariteta», amb Peret mort i cuinat per la madrastra, menjat pel pare, soterrat per la germana, reencarnat en forma de perera que parla i finalment ressuscitat, no és sinó una combinació d'aquest dos tipus, 720 i 780: en qualsevol cas, una rondalla clarament diferent a les del tipus 327A.

SCRIPTA, Revista internacional de literatura i cultura medieval i moderna, núm. 17 / juny 2021 / pp. ISSN: $2340-4841 \cdot$ doi:10.7203/SCRIPTA.17.20924 
Joan Borja i Sanz. Aportacions i referències etnopoètiques en l'obra literària de Carmelina Sánchez-Cutillas

havia consultat epistolarment a l'escriptora alguns dubtes lèxics de l'intricat, dens, erudit, enigmàtic i en molts moments impenetrable poemari Els jeroglifics i la pedra de Rosetta (1976).

En la seua carta, datada el 4 de gener de 1997, Lluís Alpera li demanava a Sánchez-Cutillas informació sobre «alguns dubtes o desconeixença sobre el següent lèxic d'Els jeroglifics $i$ la pedra de Rosetta». I hi apuntava set paraules procedents de contextos culturals més o menys exòtics: mu, Masfa, Ticho, Malec, karima, taub i abaia. Tanmateix, en l'esborrany de la carta de resposta, Carmelina li fa també una explicació sobre la paraula seguissets, estratègicament present en el «Poema 24» d'Els jeroglifics i la pedra de Rosetta. I és el cas que ací torna a aparéixer referenciat el personatge de la mare Paula: «Quan jo era xicoteta, la mare Paula (a la qual trac a la meua Matèria [de Bretanya]) aplegava un moment que es fartava del núvol de xiquets, i ens deia "hala, a caçar gambosins i a espigolar seguissets"». Animalets i plantes fantàstiques. No sé d'on se l'hauria tret, però era molt vella».

Aquesta anotació de Carmelina permet de documentar, per primera i única volta, l'existència dels seguissets en l'imaginari popular valencià: com una planta fantàstica, equivalent als gambosins, en el regne vegetal; una mena d'éssers vegetals màgics que poden ser espigolats de la mateixa manera que els gambosins, animals imaginaris, poden ser caçats. «Hala! A caçar gambosins i a espigolar seguissets!» Amb aquest aclariment de Carmelina a Lluís Alpera podem entendre el just sentit de la paraula seguissets en el corresponent context de l'al ludit «Poema 24» del críptic poemari Els jeroglifics i la pedra de Rosetta: «Tot açò són sediments de vells records amagats als claustres de la memòria, i ara tornen a la vida com fulles màgiques dels seguissets o com les veus perdudes».

Es tracta, així, doncs, d’un element llegendari popular: les «fulles màgiques dels seguissets» són redimides en el poemari de Carmelina -ara ho sabem- gràcies a «les veus perdudes» procedents «de vells records amagats als claustres de la memòria» que retornen a la vida gràcies a la remembrança d'un dels personatges més entranyables de l'univers literari de Carmelina: «la mare Paula». I val a dir que aquesta adscripció que Carmelina en fa, dels seguissets, a la veu i la memòria de la mare Paula, d'Altea, és particularment interessant i suggeridora si tenim en compte que la paraula seguissets és, potser, tan intrigant i màgica com efectivament desapercebuda i poc coneguda. Pràcticament només en l'obra de Salvador Espriu en podem documentar un cert aprofitament literari. El poeta de Santa Coloma de Farners, en la composició «Els Tres Reis d'Orient», de Les cançons d'Ariadna (1949), feia referència a Sembobitis, l'assistent sortiller del rei Baltasar. I hi escrivia, a colp d'heptasíl labs:

El servia, fidelíssim,

Sembobitis, conseller,

màgic i metge, sortit

de l'antiga escola d'On.

Coneixia mil secrets

i l'espant de l'encanteri

de l'herba de seguissets.

SCRIPTA, Revista internacional de literatura i cultura medieval i moderna, núm. 17 / juny 2021 / pp.

ISSN: 2340-4841 · doi:10.7203/SCRIPTA.17.20924 
Joan Borja i Sanz. Aportacions i referències etnopoètiques en l'obra literària de Carmelina Sánchez-Cutillas

No és l'única ocasió en què Espriu es refereix a aquesta misteriosa «herba de seguissets», pròpia de fetilleries, encanteris i sortilegis. També en la Primera història d'Esther (1948), quan parla de les facultats màgiques de la Neua, la Bòtil, la Coixa Fita i la Narcisa Mus, l'autor de Cementiri de Sinera deixa caure: «ni les bruixes de Vallgorguina no les guanyarien a manetes, tocant al punt i xup-xup del teto calent o del brou de l'herba de seguissets».

També a Mallorca Biel Mesquida es va referir, més recentment, a aquestes intrigants plantes en un text publicat en el Diario de Mallorca, el dia 30 de gener de 2011. «Records de futur», es titulava. I hi podem llegir: «He demanat a una bruixa amiga meva que em trobi l'herba de seguissets». Segons el Diccionari català-valencià-balear d'Antoni Maria Alcover i Francesc de Borja Moll, els seguissets són «una herba màgica imaginària per a encisar i fer seguir algú». No debades, l'accepció seguissets hi remet a l'entrada seguitori que conté la definició següent: «Bevenda màgica per a atreure i dominar algú; l'efecte d'atracció que produeix».

Comptat i debatut, els seguissets són, per tant, unes plantes màgiques que permeten fer conjurs, pocions i beuratges per a embruixar, embadocar, seduir, encativar, encisar, seduir i enamorar. Per a «fer seguir algú» amb la força d'un sortilegi, a la manera dels anomenats filtres d'amor. I no deixa de ser curiós que siga la mateixa mare Paula, d'Altea -el personatge que matriarcalment encarna el prodigi de la meravella i la fantasia en el deliciós univers memorialístic de Matèria de Bretanya- qui, precisament, segons el record de Carmelina, apel lara a l'imaginari dels gambosins i els seguissets quan «es fartava del núvol de xiquets» que sempre tenia al voltant.

No debades, l'atracció de Carmelina Sánchez-Cutillas per aquest personatge de la mare Paula queda testimoniada amb el fet que se'n conserva un poema mecanoscrit, inèdit, el motiu del qual coincideix en essència amb el contingut del mateix capítol «Remembrança» de Matèria de Bretanya:

\author{
La mare Paula, d'Altea \\ La mare Paula \\ vivia al barri del Fornet \\ - carrer dels baladres-. \\ La mare Paula \\ alletava el meu cosí; \\ un nen esquifit i negre \\ i més amarg que la ruda.
}

\begin{abstract}
7 Conservem l'original d'aquest poema mecanoscrit en el nostre arxiu personal gràcies a Marisa del Romero SánchezCutillas, filla de Carmelina, que ens el va voler obsequiar l'any 2011 per raons de caràcter familiar. La coincidència entre el poema i el capítol «Remembrança» porta a sospesar si, en el procés de creació, Carmelina va escriure primer el capítol i després en va compondre el poema, com una mena d'extracte; o si, per contra -molt més probablement, al nostre parer-, primer va compondre el poema i després en va redactar la prosificació. Siga com vulga, la composició mecanoscrita no deixa de demostrar l'interés especial que l'autora demostrava tenir per aquest personatge simbòlicament representatiu del patrimoni etnopoètic.
\end{abstract}


Joan Borja i Sanz. Aportacions i referències etnopoètiques en l'obra literària de Carmelina Sánchez-Cutillas

\author{
Les tardes de pluja \\ la mare Paula \\ ens contava contes estranys, \\ i a l'hora del berenar \\ tots li'n demanàvem \\ el coret de la melva. \\ (Són records d'altres dies, però.) \\ I per sentir-nos de cridar \\ ens esquitxava el rostre \\ amb la seva llet tèbia. \\ Quan soterraren la mare Paula \\ vaig soterrar moltes coses.
}

\title{
3. «La mestra Cantarrana explicava coses molt boniques»
}

Un altre personatge matriarcal i acollidor que, en Matèria de Bretanya, encarna la tradició literària popular és la mestra Cantarrana. L'autora ens la representa «sempre aixoplugant nens en la seua costura com una mena de mare o com una mena de lloca» (1976: 94). Igual com en el cas de la mare Paula, el record d'aquesta matriarcal mestra apareix vinculat a la narració de relats fantàstics que no deixen de representar, d'alguna manera, el patrimoni etnopoètic vindicat per l'autora. De més a més, les mostres de la cultura popular que aquest entranyable personatge recreava amb les xiquetes que tenia al seu càrrec ens són explícitament presentades com una alternativa lúdica, refrescant i desensopidora, per contraposició a la cultura ortodoxa i oficial que, dins i tot del sistema educatiu, representava la religió catòlica:

\footnotetext{
A vegades la mestra Cantarrana ens feia resar massa, i en acabant, per llevar-nos l'ensopiment del res, ens explicava coses molt boniques. Deia que la lluna era feta de trossets de miralls i era l'estatge d'un vellet que sempre duia un feix de llenya seca a l'esquena, i que quan la lluna era sencera, bé, però quan era una llesca de lluna a punt d'anar-se'n a l'altra banda del món, el vellet amb prou feines podia romandre. I les estrelles eren les finestres del cel, per on els àngels ho tafanejaven tot. I els núvols eren dolços perquè els feien de sucre, com aquell cotó de sucre que venien al porrat de Sant Miquel (1976: 93).
}

Des d'una perspectiva etnopoètica és particularment interessant, en aquest passatge, la referenciació del motiu del vellet que viu a la lluna amb un feix de llenya seca a l'esquena. Fet i fet, si bé es mira, el relat recordat per Carmelina en boca d'aquest deliciós personatge que és la mestra Cantarrana permet una clara i evident adscripció al tipus ATU internacional 751E*, «Man in the Moon». Si el resum per a aquest tipus en The Types of International Folktales apunta que «This miscellaneous type includes various narratives dealing with a man (woman, animal, object) on the moon» (Uther 2004: 404), l'adaptació redactada per Carme Oriol i Josep Maria Pujol en la base de dades RondCat és 
Joan Borja i Sanz. Aportacions i referències etnopoètiques en l'obra literària de Carmelina Sánchez-Cutillas

encara més pròxima a la versió de la mestra Cantarrana evocada per Sánchez-Cutillas: «Un home roba un feix d'arços, de nit, per evitar que el vegin. Com a càstig, la lluna se l'emporta. Per això, a la lluna s'hi veu la cara d'una persona». ${ }^{8}$

No deixa de ser curiós el fet que, d'acord amb la referida base de dades en línia, RondCat, el tipus ATU 751E* consta com a documentat a Mallorca, en les versions d'«Es jai de sa lluna», d'Antoni Maria Alcover (2013: 343-345); a Catalunya, en «Perquè la lluna té fesomia de persona», «Una altra de perquè la lluna té fesomia de persona» $\mathrm{i}$ «De què vénen els estels del lladre-pomes», de Joan Amades (1950: 860 i 865), «L'home de la lluna», de Pau Bertran i Bros (1989: 239), «L'home de la lluna», de Pep Coll (1989: 125), «Per què a la lluna s'hi veu una ombra humana», de Camil Geis (1935: 27-28), «L'home dels arços», «Treballar en diumenge», «La lladre d'arços», «L'origen de la lluna», «El lladre de raïm», «L'home dels arços i el mal caçador» de Cels Gomis (Samper 2015: 58-62); al Carxe, en «L'home de la lluna» i «Lluna, traga mel», d'Ester Limorti i Artur Quintana (1998: 118-119); i a la Franja d'Aragó, en «L'home de la lluna», d'Artur Quintana (1995: 183). Tanmateix, figura que no ha estat mai documentat en cap recull rondallístic del País Valencià, per la qual cosa aquesta referència de Carmelina en Matèria de Bretanya, entre les «coses molt boniques» que explicava la mestra Cantarrana, té el valor afegit de constituir ara mateix la primera i única documentació d'aquest motiu universal ATU $751 \mathrm{E}^{*}$ dins del context cultural estrictament valencià.

L'anècdota ens sembla particularment significativa si tenim present que el personatge de la mestra Cantarrana, com la mare Paula, representa l'autenticitat de la cultura popular del poble protagonista de Matèria de Bretanya no solament pel cantó de la llengua, sinó també, i d'una manera molt especial, pel que fa al món de meravelles que el patrimoni etnopoètic enclou i que l'autora no s'està de contraposar a l'opressió que significava l'educació reglada exercida per l'escola de monges a la ciutat. D'aquesta manera, la dicotomia entre poble i ciutat ens és hàbilment connotada en l'obra, al costat de tota una altra sèrie de dicotomies, que permeten traçar una mena d'eixos ideològics que discorren, respectivament - des del plànol dels valors positius fins al dels valors negatius-, entre la

8 http://rondcat.arxiudefolklore.cat [Data de consulta: abril de 2021]

9 En el capítol «El cèrcol i el bassot» es relata el moment en què l'avi de l’escriptora, Francesc Martínez i Martínez, pren la decisió de portar la xiqueta Carmelina a l'escola de la mestra Cantarrana per propiciar que, en contacte amb les altres xiquetes del poble, puga aprendre valencià. Aquesta decisió, que Carmelina no s'estalvia de rememorar, es pren just després d'un incident que es desencadena quan Carlos, el germà de Carmelina, es baralla amb un altre xiquet, li agafa el cèrcol i li’l llança dins d'una bassa: «Però en aplegar a casa i oblidant les convidades de ma mare vaig començar a cridar des de la porta, “mamá, Carlitos ha tirado un cerdo al agua». I gràcies que Maria Ronda mig plorant de tant de riure’s, va explicar el lapsus linguae, perquè si no els calbots haurien estat ara per al meu germà. / Al meu avi no li va fer gens de gràcia, i deia que era una vergonya que els seus néts no sabien parlar valencià. Del que farien amb els meus germans no me'n recorde, però sobre la meua persona va disposar que aniria a costura perquè, amb el tracte amb les altres xiquetes del poble, pogués adquirir una millor coneixença idiomàtica. I així fou com a l'endemà, amb la cadireta de boga i un tros de pa i companatge, em dugueren a la casa de la mestra Cantarrana, com li deien de malnom» (1976: 57). 
Joan Borja i Sanz. Aportacions i referències etnopoètiques en l'obra literària de Carmelina Sánchez-Cutillas

fantasia i la realitat, entre la imaginació i l'ortodòxia, entre l'estiu i l'hivern, entre la companyonia espontània i el constrenyiment repressor, entre el valencià com a llengua popular d'Altea i el castellà com a llengua oficial a València, entre la llibertat dels carrers i els camps del poble i la reclusió asfixiant de l'internat religiós a la ciutat:

\footnotetext{
Però d'un any enllà em van tancar a un col legi a ciutat, i un dia li vaig contar a una monja allò que sabia de la lluna i el vell, i dels estels i els núvols, però la monja s'avalotà i va avalotar la comunitat, i totes deien «Señor, cuánta incultura». Després em preguntaven qui m’havia ficat al cap aqueixes barbaritats. Tanmateix, no vaig voler parlar de la mestra Cantarrana, sempre aixoplugant nens en la seua costura com una mena de mare o com una mena de lloca. I no sé com ho van fer, però a poc a poc m'ho esborraren tot de la memòria. I sentia la gran buidor que duia dintre i em preguntava si les persones quan estarien buides del tot, tan terriblement buides com jo, seria per morir. I no (1976: 94).
}

S'entén que aquest esborrament de la memòria i la conseqüent gran buidor admeten -talment com en el conjunt de l'obra, en què la membrança personal adquireix alhora el significat d'una memòria col lectiva- una lectura en clau simbòlica, en què l'esborrament de la memòria popular compartida (això que en termes acadèmics en podríem dir el patrimoni etnopoètic) sembla que podria conduir a la mort del poble valencià, el qual, tanmateix, a pesar de les dificultats totes, és capaç de resistir i de sobreviure enmig de les greus adversitats històriques que hi ha comportat la desmemòria, la dissidència lingüística i, en definitiva, la despersonalització cultural.

\section{4. «I tots cantant»}

Com les rondalles, també les cançons contribueixen d'una manera eficient a adobar els records literaturitzats en Matèria de Bretanya amb una característica pàtina de melangia, fantasieig i sabor popularitzant. Així, en la descripció del dinamisme evocat als carrers d'Altea, Sánchez-Cutillas no s'està de remembrar: «Eren uns carrers plens de vida i de llum i de moviment, plens de crits i de paraules, de plors de xicons que es barallaven i de cançons de mares dormint els fillets» (1976: 28).

Així mateix, en «El llamp i la sageta dels records» (Sánchez-Cutillas 1979) -que és com una mena de colofó per a Matèria de Bretanya, en què es literaturitza, per fi, la guerra mai no esmentada en l'obra de 1976-, l'autora instrumentalitza hàbilment tant el simbolisme del cant religiós de la mare quan és obligada pel Comité de l'Olla a pelar ametles («ma mare llevava les corfes de les ametles al compàs del Cantemos al Amor de los Amores, cantemos al Señon; 1979: 200-201) com el dels himnes marcadament ideològics - tots en llengües forasteres: 
Joan Borja i Sanz. Aportacions i referències etnopoètiques en l'obra literària de Carmelina

Sánchez-Cutillas

\begin{abstract}
Qualsevol guerra, qualsevol revolució té el seu himne, però no sé si la música i els versos neixen del fet guerrer, o si és aquest el que comença i brolla només eixir dels llavis del poble les primeres estrofes, sempre bellíssimes, d'un cant de llibertat, d'independència. Quan proclamaren la República mon pare ens va ensenyar La Marsellesa, "Allons enfants de la Patrie / le jour de gloire est arrivé...» [...] Quan arribàvem, el tio Patilla ja ens havia tallat unes canyes del seu canyar, verdenques i sense desfullar. I nosaltres, amb les llances-canyes, pegant voltes a l'entorn de la casa i de la cisterna, per les vores del forn de coure i del corral, pujant a la barca quan s'assecava al sol amb la carena encara humida: Marchons, marchons... En acabant, berenàvem (1979: 201-202).

I ara, asseguts al marge de la carretera i aprenent els himnes que cantaven els guerrers dels camions també el recordàvem: Hijo del pueblo, / te oprimen las cadenas / y esa injusticia no puede seguir / si tu existencia es un mundo de penas / antes que esclavo prefiere morir... A mi el que més m'agradava de tots era el que deia: A las barricadas / vamos a luchar..., però fa tota una vida que no l'he tornat a sentir i n'he oblidat la resta; només guarde, a la memòria, que aquells himnes empentaven els homes a la guerra, els empentaven a la mort.

Els xiquets no enteníem massa bé allò de la guerra dels grans, encara que també ens van escriure el nostre cant: ...no tememos la muerte, / es la ley del fuerte / vencer o morir... L'únic que enteníem era que la mort s'ajocava molt propet de nosaltres, i que qualsevol dia la veuríem aplegar (1979: 202).
\end{abstract}

Tornant a Matèria de Bretanya, quan en el capítol «La Quaresma» Carmelina recrea literàriament el costum de la salpassa, el dimecres sant de matí (una tradició que consistia a beneir les cases amb el salpasser i a anar omplint els saler dels veïns, a canvi dels ous que els feligresos obsequiaven als religiosos), no s'està de transcriure'n jocosament, ja en vernacle, la lletra que tradicionalment s'hi cantava:

\footnotetext{
Una colla de xicons seguia la comitiva, alguns amb cistelletes per ajudar a l'arreplega, i tots cantant, «Ous, ous, bones Pasqües, bons dijous, la gallina en l'olla, bones bastonades al Pare Guardiola». I en acabant cascun rector repartia els ous entre ell, els xicons del cant i els qui duien les cistelles, i els monesillos dels atifells de la salpassa (1976: 75).
}

Fet i fet, el cançoner popular no deixa de ser, en Matèria de Bretanya, un signe de la llibertat i de l'espontaneïtat que els carrers i els xiquets d'Altea representaven. Ho il lustra clarament el passatge del capítol «La mestra Cantarrana» en què es descriu la felicitat dels xicons quan feien campana, se n'anaven a prendre el bany nus al Clot de Mingot i culminaven la festivitat de l'instant cantant joiosament:

hi havia canyars i baladres $i$ els xicons aprofitaven l'herbat per a despullar-se, i es tiraven al bassol en conill i semblaven peixos, peixos lliscant entre un sostre d'aigua al damunt i un sòl 
Joan Borja i Sanz. Aportacions i referències etnopoètiques en l'obra literària de Carmelina Sánchez-Cutillas

d'aigua dessota. Quan s'havien eixugat prou, se n'anaven cap als tossals i els barrancs a fer margallons, i cantaven «Don Francisco Xinosa, puja a cavall de la gossa» (1976: 90).

Sense eixir d'aquest mateix capítol dedicat a la peculiar mestra Cantarrana, trobem un altre exemple en què una oració que cantaven les xiquetes de costura, a pesar «que no tenia trellat», és recordada $\mathrm{amb}$ una afectivitat que contrasta amb la indiferència i l'avorriment que inspiraven les oracions oficials que la mestra volia ensenyar-los. És com si la fantasia popular hi constituïra un referent o una força aliada en la íntima rebel lió de l'autora contra el món de les estructures, els poders i els dogmes establerts:

\begin{abstract}
abans d'aprendre les oracions de la senyora Llúcia, vaig aprendre una altra que cantaven les xiquetes ben baixet $i$ amagant-se, perquè no tenia trellat, $i$ era una oració que encara no he pogut oblidar i que diu, «Santa Maria, la rata corria sota la cadira, el gat l'acaçava i ella se'n fugia» (1976: 92).
\end{abstract}

Aquest valor de la rebel lió vinculat a la desinhibició o al desficaci del cançoner popular torna a manifestar-se poques pàgines més avant, en el capítol «Quan anàvem a la Ribera», en el moment que les dones preparen el recapte dels homes i la simple imatge d'un setrill li fa vindre a la memòria una cançó que sa mare qualificava de «muy ordinaria». La coacció repressiva, representada per la mare, li prohibeix de cantar-la; però ella no per això deixa de cantussejar-la en veu baixa. És, aquest, també, un signe de la rebel lió que la protagonista cova en el seu fur intern:

\begin{abstract}
Només de veure el setrill em venia a la memòria una cançó molt ximple que deia, «Maria la xerevia, trencadora de setrills, que es pixa davant dels xics fadrins...» i la cantava baixet perquè ma mare no em deixava cantar-la, car deia que era «una canción muy ordinaria» (1976: 96).
\end{abstract}

Fins i tot, en el capítol «Sant Cristòfol i el xiquet» podem trobar una referència al gènere popular per antonomàsia de la cançó popular religiosa valenciana: els goigs. I en la referència, Carmelina no s'està de comentar hàbilment el fet que aquests goigs en honor al Santíssim Crist del Sagrari eren ja cantats en castellà per raó dels efectes castellanitzadors de l'Església: ${ }^{10}$ aquesta transmutació generava una percepció de llengua impròpia per als mateixos feligresos, els quals en cantaven la lletra amb una pronúncia macarrònica que, fins i tot, n’entrebancava la comprensió:

10 A Altea s'han pogut documentar, a part d'aquests goigs referits per Carmelina (que són els que encara es continuen cantant, popularment), uns altres goigs al Santíssim Crist del Sagrari, del segle XIX, que sí que eren en valencià (Borja 2000: 39). 
Joan Borja i Sanz. Aportacions i referències etnopoètiques en l'obra literària de Carmelina

Sánchez-Cutillas

el mestre, sempre prim i amb un posat trist que feia pena de mirar-lo, encetava els «Goigs al Santíssim Crist del Sagrari». Feia tan, i les dones «San...», i ell ti to ti, i les cantores «...acristo verdadero, mi dolensiai mis pecados...» Per això jo no entenia bé el que cantaven, i em costà una pila d'anys de saber-ho. Però aleshores hi havia moltes altres coses que jo no entenia (1976: 181).

\section{5. «No podia destriar els fets reals dels fantàstics»}

Com les rondalles i les cançons, també els motius llegendaris són adesiara presents en Matèria de Bretanya $^{11}$ al servei d'aquesta estratègia literària que consisteix a presentar els records objecte de literaturització embolcallats amb una mena de boirina màgica que invita el lector a compartir la innocent $\mathrm{i}$ impressionable perspectiva de la xiqueta que narra els fets: una perspectiva difuminada per una tal permeabilitat i propensió a la meravella que impedeix -com la mateixa Carmelina apunta- «destriar els fets reals dels fantàstics».

Així, per exemple, en el capítol «Les coses que sabíem», Carmelina no s'estalvia el gust de donar compte de les propietats màgiques que, segons la creença popular, la planta de la ruda podia oferir com a antídot repel lent de bruixes i de dimonis, com tampoc les pràctiques supersticioses que, d'acord amb aquesta llegenda, se solien dur a terme en relació amb les suposades propietats exorcitzants d'aquesta singular planta quan naixia una criatura i la bolcaven:

I no sé si seria per la pudor o per què, però és el cas que la ruda espantava les bruixes, i per això quan naixia un nen la comare posava una branqueta de ruda en la finestra de la cambra de la partera, i la ficava dins d'un got ple d'aigua per fer-la durar més dies. I quan bolcaven el nen de bolquers, també li lligaven una altra branqueta de ruda, i li la lligaven amb la mateixa agulla del reliquiari de domàs brodat que duien totes les criatures. I en acabant la mare i les àvies i

11 També en «El llamp i la sageta dels records» podem documentar, ni que siga de passada, un peculiar motiu llegendari. Es tracta del passatge en què la mare de Carmelina és obligada pel Comité de l'Olla a pelar corfes d'ametles i el pare li aconsella que tinga prudència. La narradora ens hi informa: «però ni prudència ni res, perquè en compte de fer com el rector de Calp - «senyor moro no em mate, que jo renegaré»-, ma mare llevava les corfes de les ametles al compàs del Cantemos al Amor de los Amores, cantemos al Señor...» (1979: 200-201) Aquesta referència al rector del Calp i a la unitat fraseològica «senyor moro no em mate, que jo renegaré» s'ha d'entendre, òbviament, amb la consideració com a hipotext de la llegenda «Primer la mort que renegar», recollida pel mateix avi de l'autora, Francesc Martínez i Martínez, tant en el primer volum de Coses de la meua terra (Martínez 1912: 118-120) com en el Llegendari valencià (1929, 133-134). En essència, aquesta llegenda narra la peripècia patida per un rector de Calp que sempre estava predicant: «Primer la mort que renegar. Ja sabeu: primer la mort que renegar!» Fins que un bon dia es va embarcar amb uns feligresos per anar a recollir petxines a l'altra banda d'Ifac. Dos bots tripulats per moros van atacar el llagut cristià. I quan el rector es va veure amenaçat amb un alfange al coll per un pirata barbaresc, de seguida va implorar: «Senyor moro, no em mate que jo renegaré!» Tal reacció va fer esclatar una rialla general, per tal com tot era un muntatge, i els suposats moros no eren sinó uns altres feligresos disfressats de pirates barbarescos per a la broma. El relat de Martínez conclou explicant que aquell rector mai més no va tornar a repetir allò de «Primer la mort que renegan»; i explica que, a partit d'aquest relat, a la Marina es va encunyar, per als qui en profit propi o pressionats per les circumstàncies acaben abjurant els seus ideals, el fraseologisme citat per Carmelina: «Com el rector de Calp: senyor moro, no em mate, que jo renegaré!».

SCRIPTA, Revista internacional de literatura i cultura medieval i moderna, núm. 17 / juny 2021 / pp. 
Joan Borja i Sanz. Aportacions i referències etnopoètiques en l'obra literària de Carmelina Sánchez-Cutillas

la comare, i les veïnes que entraven a tafanejar l'aixovar del menut i el cobertor del llit de la partera, sospiraven tranquil les perquè gràcies als dos amulets ja no se'l podrien emportar ni les bruixes ni el dimoni (1976: 84).

En aquest mateix capítol, parlant de la celebració de Tots Sants, Carmelina també reporta el curiós i intrigant motiu llegendari dels focs follets: unes «flames tremoloses, d'un verd blavós» que, segons l'imaginari popular, es poden aparéixer de nit als cementeris ballant «com si les empentàs el vent» en «una dansa de flametes sense trellat». ${ }^{12} \mathrm{I}$, al costat d'aquest curiosíssim motiu llegendari dels focs follets, l'autora situa igualment la creença popular segons la qual «la nit del dia de Tots Sants» les ànimes dels difunts tornen a casa i s'escampen pertot arreu:

\begin{abstract}
Els morts feien focs de flametes tremoloses, d'un verd blavós, i diu que les flametes eixien dels ossos llurs. I si caminaves de nit pel camí del cementeri, te n’eixien les llums al mig del camí i vinga de ballar com si les empentàs el vent, i era una dansa de flametes sense trellat, i per això la gent els anomenava focs follets. Però la nit del dia de Tots Sants les animetes dels morts s'escampaven pertot arreu, i el mateix te les trobaves ajocades al costat del Baluard, com en la platja o caminant pels tossals (1976: 86).
\end{abstract}

Set capítols més endavant l'autora apunta el motiu de les rogatives en temps de sequera: un fenomen absolutament recurrent i lògic en el llegendari religiós valencià, per tal com en el clima mediterrani l'aigua és un bé tan crucial com irregular:

\begin{abstract}
Si passava el temps i no plovia, els senyors rectors feien reunió a la casa abadia i acordaven de treure en processó les imatges més milagroses [sic] de l'església. I jo em preguntava si seria per la pluja o per distreure la gent (1976: 127-128).
\end{abstract}

En relació amb el mateix motiu de l'escassetat de l'aigua - «el poble patia set d'aigua», hi arriba a escriure (1976: 127)-, l'autora tracta també de les cisternes i s'hi deté a aportar un curiós detall del pensament màgic valencià, que apunta al fet que, perquè l'aigua de les cisternes no es corrompa,

12 En el context cultural valencià es coneixen molt poques referències etnopoètiques a aquest motiu llegendari dels focs follets o ignis fatuus. Literàriament, Jesús Ernest Martínez Ferrando fa referència als «foscos follets» [sic] en La botiga dels llibres vells (2001: 108-109); Lluís Guarner s’hi refereix en un parell de versos de la Cançó marinera, «La lluïssor de la lluna / fa focs follets a la platja» (1956: 146); i Maria Beneyto al ludeix a aquest fenomen llegendari en Ratlles a l'aire (1956: 28): «Nosaltres, els callats, muts, pescadors. / Hem vist amb llum / dels focs follets marítims / el tremolar fosquíssim que s'engronsa / per avisar presències inefables i eternes». Tanmateix, no ens consta que en cap recull de llegendes -ni en cap altre treball específicament etnopoètic- aquest motiu llegendari haja estat recollit i documentat.

SCRIPTA, Revista internacional de literatura i cultura medieval i moderna, núm. 17 / juny 2021 / pp.

ISSN: 2340-4841 · doi:10.7203/SCRIPTA.17.20924 
Joan Borja i Sanz. Aportacions i referències etnopoètiques en l'obra literària de Carmelina Sánchez-Cutillas

aquestes s'han d'omplir quan la lluna fa ple al mes de gener: ${ }^{13}$ «I la cisterna havien d'omplir-la al mes de gener, quan la lluna era més gran, perquè si no ho feien així l'aigua es podria» (1976: 127).

Tanmateix, la llegenda amb una significació major de tot Matèria de Bretanya és, sens dubte, la que Carmelina referencia en l'últim i estratègic capítol: el que dona nom al conjunt de l'obra. Es tracta de la llegenda del cavaller Rotlà, el Puigcampana i l'illa de Benidorm que l'avi Francesc Martínez i Martínez contava a la neta: ${ }^{14}$

\begin{abstract}
I pels mateixos senderons que aleshores petjaven aquells homes, i pel pedregar, havia passat en temps remotíssims un guerrer alt com un pi i valent com un sant Jordi que s'anomenava Rotlan, i era un dels dotze pars de la Cort de Carlemany de França. Però el cavaller Rotlan no cercava herbes, sinó que perseguia la seua nóvia que se n’anava amb un altre; per això, creuant valls i rius i serralades aplegà al Puigcampana, i furiós, pegant coltellades i bramant, d'un colp va tallar un tros d'aquesta muntanya que caigué en la mar davant mateix de Benidorm, i en comptes d'afonar-se es va quedar surant com una illa. I des d'aquell punt i hora el tall de Puigcampana es diu «la coltellada de Rotlan».

A mi m’hagués agradat molt conèixer el guerrer Rotlan, i li demanava al meu avi que em contàs més històries d'aquelles, però com que en sabia tantes jo m’embolicava i no podia destriar els fets reals dels fantàstics (1976: 190-191).
\end{abstract}

Fet i fet, d'acord amb una calculada imbricació entre la tradició literària oral i el pòsit històric de la literatura escrita, aquest passatge citat sobre la llegenda del cavaller Rotlà és immediatament posat en connexió amb l'univers literari dels antics cavallers protagonistes de la matèria de Bretanya que titula el conjunt i que apareix catafòricament anunciada en la cèlebre citació de Jean Bodel que encapçala el llibre: «Ne sont que trois matières à nul homme attendant, De France et de Bretaigne et de Rome le grant» (1976:

13 Aquest costum d'omplir les cisternes durant la lluna plena del gener és ben conegut en la cultura popular valenciana. A Beniarjó, en una visita guiada a l'interior de la cisterna i l'aljub que abastien d'aigua l'antic palau dels March (en el marc de les VII Jornades Literatura, Territori i Educació, el 7 d’abril de 2019), el senyor Joan Francesc Simó va explicar que era costum omplir les cisternes en la lluna vella de gener per evitar que l'aigua s'hi fera malbé. La professora Assumpció Molina Penalva ens va testimoniar en aquella ocasió que aquesta creença també era seguida a Crevillent, al Baix Vinalopó. I la professora Francesca Cano i Server, de Polop (a la Marian Baixa) no solament ens en corroborava el testimoni, sinó que hi afegia que és també en lluna vella quan convé tallar les canyes perquè queden dures, sanes i llises. A aquesta mateixa professora Cano devem la vinculació entre aquestes propietats popularment atribuïdes a la lluna de gener amb una coneguda unitat fraseològica: «Amor, el primer; i lluna, la de gener». Es tracta d'un refrany que apareix amb la variant «D’amors, el primer / de llunes, la de gener» en el Calendari de refranys de Manuel Sanchis Guarner (1951: 11), i que és ben conegut al llarg i l'ample del domini lingüístic, atés que apareix referenciat en reculls fraseològics publicats - per exemple- a la Ribera, l’Horta Oest, el Baix Empordà, Mallorca, Eivissa, el Segrià, la Catalunya Nord, la Costera, la Vall d'Albaida i Barcelona.

14 En efecte, la versió de la llegenda de Rotlà reportada ací per Carmelina és coincident amb la recopilada per Francesc Martínez i Martínez en tres dels seus llibres: el primer volum de Còses de la mena tèrra (la Marina) (1912: 103-105), Folklore valencià. Arreplega de llegendes, tradicions y costums del Reine de Valencia (1927: 131-136) i Llegendari valencià (1995: 150-152). Sobre aquesta llegenda del cavaller Rotlà, el Puigcampana i l'illa de Benidorm vegeu Borja (2014: 15-37).

SCRIPTA, Revista internacional de literatura i cultura medieval i moderna, núm. 17 / juny 2021 / pp. 
Joan Borja i Sanz. Aportacions i referències etnopoètiques en l'obra literària de Carmelina Sánchez-Cutillas

21). Així, doncs, si seguim el fil discursiu proposat per la innocent veu de la xiqueta, just a continuació podem acabar de comprendre la clau del poètic i captivador joc de fusions, confusions, efusions i difusions -d'imprecises i suggeridores fronteres entre realitat, somni, memòria, imaginació, història i ficció- que, en últim terme, és l'obra de Carmelina:

\footnotetext{
Tanmateix m'estimava viure així, perquè era com si m’hagués esbaltit però sabent que estava ben desperta, i si a voltes em semblava escoltar les cavalcades d'uns cavallers que diu que vivien a l'entorn d'una taula redona, prenia uns granets de matafaluga i en mastegar-los i sentir-me la boca plena del seu flaire m'adonava de l'embruix del passat, i per deslligar-me'l encara més, i saber de bon de veres que jo no era una criatura d'un somni sinó una xiqueta de carn que alenava i vivia al món, me n'anava corrent on eren els altres xiquets a barallar-me o a jugar amb ells (1976: 191).
}

És d'aquesta manera, per tant, que podem col legir quin és el significat últim de l'escena que clou el llibre, quan el foraster que es troba de visita a la casa de l'avi li allarga els llibres antics «relligats en pergamí» que han trobat en un amagatall, amb «tot el cicle bretó». Són «un paquet embolicat en tela de fer coixineres». I quan el viatger, a poqueta nit -quan la mar «tenia aqueixa color d'aigua adormida que pren a l'horabaixa, quan la llum del far inicia el joc amb les ombres» (1976: 195)-, li allarga aquest «embolic de tela» que són aquells llibres: «comença a riure, i com que mon avi volia saber el motiu ell va dir «que no la veu?, tan xicoteta i acabe de deixar entre les seues mans tota la Matèria de Bretanya».

\section{A tall de conclusió: «tota la Matèria de Bretanya»}

Aquest últim sintagma del llibre, «Matèria de Bretanya», és -ja ho hem dit- el que dona títol al capítol i també al conjunt de l'obra. ${ }^{15}$ Entenem que el gest de rebre entre les mans aquell valuós paquet apel la simbòlicament, en el context en què es produeix, no solament al conjunt de novel les i textos bretons que difonen l'ideal de la novel la cavalleresca a l'Europa medieval, sinó, en realitat, al conjunt de la tradició literària universal. Podem entendre que apel la, en últim terme, a la cultura del llibre, en general, però també a la literatura popular oral: la que s'acaba d'exemplificar amb la llegenda del cavaller Rotlà i el Puigcampana (íntimament vinculada en aquest capítol al motiu dels cavallers de la taula redona i els llibres de cavalleria); la que, al llarg de tota l'obra, tal com hem tingut oportunitat de comprovar, amera el text de rondalles, llegendes, creences, cançons, etc.. No debades, «tota la Matèria de Bretanya» que el foraster erudit lliura a la xiqueta Carmelina embolicada en tela

15 En un moment determinat del dilatat procés de gestació, Carmelina va sospesar, com a possible títol per al conjunt de «quadrets» que integren l'obra, l'alternativa Un camí per la memòria. Si més no, aquest és el sintagma que provisionalment consigna en la carta que adreça a Manuel Sanchis Guarner el 23 d'abril de 1969, quan li'n fa arribar l'original amb un total de 25 capítols: «a tot el conjunt li donaria més o menys el títol de Un camí per la memòria» (Del Romero 2020: 114).

SCRIPTA, Revista internacional de literatura i cultura medieval i moderna, núm. 17 / juny 2021 / pp. ISSN: 2340-4841 $\cdot$ doi:10.7203/SCRIPTA.17.20924 
Joan Borja i Sanz. Aportacions i referències etnopoètiques en l'obra literària de Carmelina Sánchez-Cutillas

és, si bé es mira, el llegat que l'avi deixa a la neta: un llegat que acaba entre les mans de Carmelina, sí, però que, al seu torn, l'avi també ha rebut en herència dels seus avantpassats; un llegat inesperat que, inadvertit durant molt de temps, li pertanyia, li era propi; tenia un valor extraordinari i estava ocult dins mateix de casa.

No ens sembla agosarat, per tant, suggerir que la «Matèria de Bretanya» potser representa, en el cèlebre llibre de Carmelina Sánchez-Cutillas, tot el conjunt de l'herència cultural i literària valenciana i universal- que el seu avi (l'historiador, bibliòfil, arqueòleg, cervantista, escriptor i folklorista Francesc Martínez i Martinez) representava al seus ulls; el pes d'una tradició cultural que no solament inclou una pàtria de paraules, la llengua, sinó també un riquíssim i valuosíssim heretatge fet amb l'art de les paraules, la literatura: la literatura de transmissió escrita, en suport llibresc, sí; però també la literatura popular de transmissió oral. Ço és: el conjunt indestriable d'una tradició literària i un patrimoni etnopoètic que, talment com els contes de la mare Paula, és alhora valencià i universal. 
Joan Borja i Sanz. Aportacions i referències etnopoètiques en l'obra literària de Carmelina Sánchez-Cutillas

\section{Bibliografia}

Alcover, Antoni Maria (2013) Aplec de rondaies mallorquines d'en Jordi des Racó, VI, Palma, Moll.

Amades, Joan (1959) Folklore de Catalunya: Rondallistica (Rondalles-Tradicions-Llegendes), Barcelona, Selecta.

Beneyto, Maria (1956) Ratlles a l'aire, València, Torre.

Bertran i Bros, Pau (1989) El rondallari català, Barcelona, Altafulla.

Borja, Joan (2000) «Sobre la llegenda del Cristo d'Altea», Cristo 2000 (setembre de 2000), Altea, Ajuntament d'Altea, p. 38-39.

—. (2014) Papers d'etnopoètica, Barcelona, Publicacions de l'Abadia de Montserrat.

Coll, Pep (1989) Quan Judes era fadrí i sa mare festejava, Barcelona, La Magrana.

Del Romero, Luis (2020) La meva cambra més estimada. La biblioteca de Carmelina Sánchez-Cutillas, València, Vincle.

Espriu, Salvador (1948) Primera història d'Esther, Barcelona, Aymà.

—_. (1949) Les cançons d'Ariadna, Barcelona, Aymà.

Geis, Camil (1935): Llibre de rondalles populars, Barcelona, Llibreria i Tipografia Catòlica.

Gonzàlez i Caturla, Joaquim (1985) Rondalles de l'Alacantí, Alacant, Institut Alacantí de Cultura Juan Gil-Albert.

Guarner, Lluís (1994) «Cançó marinera», dins Joan Fuster, Antologia de la poesia valenciana (19001950), València, Tres i Quatre. [Edició original de 1956]

Jason, Heda (1977) Ethnopoetry: form, content, function, Bonn, Linguistica Biblica.

Limorti, Ester i Artur Quintana (1999) El Carxe. Recull de literatura popular valenciana de Múrcia, Alacant, Institut de Cultura Juan Gil-Albert.

Martinez Ferrando, Jesús Ernest (2001) La botiga dels llibres vells, Alzira, Bromera. [Edició original de 1919]

Martínez i Martínez, Francesc (1912) Còses de la mena tèrra (La Marina). Primera tanda, València, Manuel Pau.

. (1927) Folklore valenciá. Arreplega de llegendes, tradicions y costums del Reine de Valencia, València, Societat Valenciana de Publicacions.

- (1995) Llegendari valencià, Alacant, Institut d'Estudis Juan Gil-Albert. [Edició de l'original de 1929 a cura de Josep Maria Baldaquí]

Oriol, Carme (2002) Introducció a l'etnopoètica. Teoria i formes del folklore en la cultura catalana, Valls, Cossetània.

Oriol, Carme i Josep Mari Pujol (2003) Índex tipologic de la rondalla catalana, Barcelona, Departament de Cultura. Centre de Promoció de la Cultura Popular i Tradicional Catalana. 
Joan Borja i Sanz. Aportacions i referències etnopoètiques en l'obra literària de Carmelina Sánchez-Cutillas

Quintana, Artur (1995) Lo Molinar: Literatura popular catalana del Matarranya i Mequinensa, I, Calaceit, Instituto de Estudios Turolenses/Associació Cultural del Matarranya-Carrutxa.

Samper, Emili (2015) Les rondalles de Cels Gomis i Mestre. Edició, catalogació i estudi, Barcelona, Publicacions de l'Abadia de Montserrat.

Sánchez-Cutillas, Carmelina (1974) Francisco Martinez i Martinez. Un bumanista alteano (1866-1946), Alacant, Publicacions de la Caixa d'Estalvis Provincial d'Alacant.

__. (1976) Matèria de Bretanya, València, Eliseu Climent.

—_. (1997) Obra poètica, València, Consell Valencià de Cultura.

(1979) «El llamp i la sageta dels records», L’Espill, 1-2 (primavera-estiu de 1979), p. 197-205.

Sanchis Guarner, Manuel (1951): Calendari de refranys, Barcelona, Barcino.

Uther, Hans-Jörg (2004) The Types of International Folktales. A Classification and Bibliography, I, Hèlsinki, Academia Scientiarum Fennica, 3 vol. 